\title{
Reversing chemoresistance of malignant glioma stem cells using gold nanoparticles
}

This article was published in the following Dove Press journal:

International Journal of Nanomedicine

28 February 2013

Number of times this article has been viewed

\begin{abstract}
Anamaria Orza ${ }^{1,2}$
Olga Sorițău ${ }^{3}$

Ciprian Tomuleasa ${ }^{3,4}$

Liliana Olenic ${ }^{5}$

Adrian Florea ${ }^{4}$

Ovidiu Pana ${ }^{5}$

loan Bratu

Emoke Pall ${ }^{6}$

Stefan Florian ${ }^{3}$

Dan Casciano ${ }^{2}$

Alexandru S Biris ${ }^{2}$

'Faculty of Chemistry and Chemical Engineering, Babes-Bolyai University, Cluj-Napoca, Romania; ${ }^{2}$ Center for Integrative Nanotechnology Sciences, University of Arkansas at Little Rock, Little Rock, AR, USA; ${ }^{3}$ lon Chiricuță Oncology Institute, Cluj-

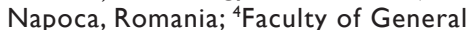
Medicine, Iuliu Hațieganu University of Medicine and Pharmacy, ClujNapoca, Romania; ${ }^{5}$ National Institute for Research and Development of Isotopic and Molecular Technologies, Cluj-Napoca, Romania; ${ }^{6}$ Department of Research, University of Agriculture and Veterinary Medicine, Cluj-Napoca, Romania
\end{abstract}

Correspondence: Anamaria Orza Faculty of Chemistry and Chemical Engineering, Babes-Bolyai University, II Arany Janos Street, Cluj-Napoca, Romania 400028

Email iorza@chem.ubbcluj.ro

Alexandru Biris

Center for Integrative Nanotechnology

Sciences, University of Arkansas at

Little Rock, 280 I South University

Avenue, Little Rock, AR, 72204 USA

Email asbiris@ualr.edu

\begin{abstract}
The low rate of survival for patients diagnosed with glioblastoma may be attributed to the existence of a subpopulation of cancer stem cells. These stem cells have certain properties that enable them to resist chemotherapeutic agents and ionizing radiation. Herein, we show that temozolomide-loaded gold nanostructures are efficient in reducing chemoresistance and destroy $82.7 \%$ of cancer stem cells compared with a $42 \%$ destruction rate using temozolomide alone. Measurements of in vitro cytotoxicity and apoptosis indicate that combination with gold facilitated the ability of temozolomide, an alkylating drug, to alter the resistance of these cancer stem cells, suggesting a new chemotherapy strategy for patients diagnosed with inoperable recurrent malignant glioma.
\end{abstract}

Keywords: gold nanoparticles, drug delivery, temozolomide therapy, temozolomide stability, cancer stem cells, recurrent high-grade gliomas

\section{Introduction}

Malignant gliomas are one of the most common primary tumors of the cerebrospinal axis and may occur in patients of any age, but tend to have two incidence peaks, ie, one at the age of 55-65 years in adults and another at 3-12 years in children. Malignant gliomas are responsible for approximately 11,000 patient deaths per year. ${ }^{1}$ The standard of care for patients diagnosed with high-grade malignant glioma includes postoperative temozolomide adjuvant to radiation. However, this therapeutic strategy is associated with considerable toxicity and limited efficacy. The median length of survival for patients with high-grade primary glial tumors ranges from 11 to 33 months after initial diagnosis, with a mean survival time of 7 months following recurrence., ${ }^{2,3}$

The failure of current approaches in the treatment of malignant glioma has been attributed to the existence of a subpopulation of cancer cells known as malignant glioma stem cells, which have the ability to withstand chemotherapeutics and ionizing radiation because of their unique properties of high antiapoptotic protein expression, high $\mathrm{ABC}$ pump expression, and a remarkable capacity for DNA repair. ${ }^{4-6}$ Traditional therapies, such as DNA alkylating or methylating drugs, along with radiation, have poor efficacy against these types of cells. Therefore, more complex treatments capable of overcoming the ability of cancer stem cells to eliminate anticancer drugs and with other protective functions are urgently needed. For this reason, a combination of traditional treatments and nanotechnology-based approaches offers attractive possibilities. More efficient and less toxic therapeutics that can cross the protective barriers on cancer stem cells are also necessary. In this context, nanomaterials could play an important role because of their unique electronic, optical, magnetic, and structural properties that are found 
neither in bulk materials nor in single molecules and which are necessary to develop advanced cancer treatments.

The ability of various gold nanoparticles to cross the blood-brain barrier after intravenous administration has been reported. Particles with the greatest ability to cross the bloodbrain barrier are those in the $15-50 \mathrm{~nm}$ size range. ${ }^{7,8}$ Herein, we demonstrate binding of temozolomide to the surface of $55 \mathrm{~nm}$ gold triangle wires and uptake of the drug in the first few hours, with progressive accumulation in the perinuclear region of glioma stem cells. This gold nanoparticle vector is a promising approach for increasing the efficacy of various chemotherapies, could increase the active life of temozolomide under physiological conditions, and may also facilitate crossing of the blood-brain barrier, thereby facilitating greater accumulation of the drug in brain cells and tissues.

Recently, gold nanoparticles have developed into an attractive candidate for the specific delivery of complex drugs, molecules, and/or biomolecules (proteins, DNA, and RNA) to their targets. Because of their ability to accumulate selectively in tumor tissue, gold nanoparticles can serve as detectors of cancer cells $\mathrm{s}^{9,10}$ or as targeted drug delivery agents. ${ }^{11,12}$ Targeted delivery of anticancer drugs specifically to the tumor site will maximize the efficacy of the drug and minimize collateral damage by reducing systemic toxicity ${ }^{13}$ and hence reduce the side effects typically associated with use of cytostatic agents in the treatment of cancer.

It is well known that a number of drugs when combined with gold nanoparticles significantly attenuate toxicity in various tumor cell lines. Several articles describing nanoparticle conjugations and their effects on different cancer types have been published. ${ }^{14,15}$ Kahn et al have studied decoration of gold nanoparticles with anti-epidermal growth factor receptor in nasopharyngeal carcinoma (CNE2) and normal human lung fibroblast cells. ${ }^{16}$ Localization of gold nanoparticles through confocal imaging increases the reflectance characteristics of the CNE2 cells, and the regions with higher reflectance values, represent areas with high epidermal growth factor receptor expression in cells. GNPs have also been conjugated with anticancer drugs, such as methotrexate and gemcitabine-epidermal growth factor receptor. ${ }^{17,18}$ In vitro tests have demonstrated that these gold nanoparticle conjugates induce accumulation of methotrexate at higher rates and in higher concentrations in tumor cells, and inhibit proliferation of gemcitabine-treated pancreatic tumor cells. Methotrexate-loaded gold nanoparticles have been shown to achieve a higher cytotoxic response in various cancer cell lines when compared to similar doses of free methotrexate. Further, Liu has shown that gold nanoparticles modified with polyethylene glycol can induce toxicity in CT26 tumor cells exposed to irradiation. ${ }^{19}$

The novel properties of nanomaterials need to be explored in order to improve traditional oncology management technologies and to develop high-profile treatments with low overall toxicity to the organism and high efficacy in targeting and destroying cancer stem cells. In the present study, we aimed to synthesize a drug delivery vector, by physically coupling an anticancer drug, temozolomide, to the surface of gold nanostructures treated with L-aspartate (GNP-Laspartate-TMZ) and to test their ability to kill malignant glioma-derived cancer stem cells. ${ }^{20-22}$ The carboxyl group from L-aspartate reduced $\mathrm{Au}^{3+}$ from tetrachloroauric acid $\left(\mathrm{HAuCl}_{4}\right)$ salt to $\mathrm{Au}$, and the amine group capped the nanoparticles and organized them into high order GNP-L-aspartate nanostructures. Recently, Kora et al demonstrated that functional groups, such as $\mathrm{COOH}$ and $\mathrm{OH}$ from gum ghatti, have the ability to reduce silver nanoparticles. ${ }^{23}$ Temozolomide was conjugated with gold nanoparticles in order to obtain the GNP-L-aspartate-TMZ delivery vector of interest. The morphological, optical, and structural characteristics of the vector were then investigated by transmission electron microscopy (TEM), along with Fourier transform infrared spectroscopy (FTIR), and x-ray photoelectron spectroscopy (XPS).

The in vitro effect of the GNP-L-aspartate-TMZ vector on malignant glioma stem cells ${ }^{20}$ was tested using MTT proliferation and Annexin V/propidium iodide apoptosis assays and compared with the effect of temozolomide alone. Our results indicated that the GNP-L-aspartate-TMZ system produced highly statistically significant results. The conjugated drug appeared to be taken up by the cells in a pattern very different from that of unbound temozolomide, as visualized by optical microscopy. By binding the gold structure to the drug, we improved the treatment of World Health Organization grade III and IV tumors in the central nervous system owing to the increased efficacy of the newly formed compound. The dimer formed by the gold nanoparticles and temozolomide was shown to be more readily absorbed intracellularly by cancerous tissue than normal tissue because of the surrounding edema and increased neovascularization. It also had increased anticancer properties in comparison with the current standard of care.

\section{Materials and methods GNP-L-aspartate nanostructure preparation}

Purified L-aspartate was purchased from Merck (Whitehouse Station, NJ, USA) and $\mathrm{HAuCl}_{4}$ from Fluka (Sigma- 
Aldrich Inc, St Louis, MO, USA). Pure temozolomide was obtained from Sigma-Aldrich (Munich, Germany). $\mathrm{HAuCl}_{4}$ and L-aspartic acid solutions were prepared in concentrations of $0.5 \times 10^{-3} \mathrm{M}$ and $1.5 \times 10^{-3} \mathrm{M}$, respectively. We slowly reduced a $50 \mathrm{~mL}$ solution of $\mathrm{HAuCl}_{4}$ at room temperature by adding $15 \mathrm{~mL}$ of aspartic acid solution. During the reaction, three color changes were observed, ie, slightly pink, red, and, finally, after 9 hours, a persistent violet color. This indicates a complex reduction mechanism involving formation of small particles that act as nuclei for growth of triangular nanostructures on their $\{111\}$ facets. The resulting product was then centrifuged at 15,000 rpm for 45 minutes and washed with Milli Q water (Millipore, Bedford, MA, USA). The purified nanostructures were redispersed in phosphate-buffered saline to give a final concentration of $2 \times 10^{-9} \mathrm{M}$. The purified aspartate nanostructures (GNP-L-aspartate) were analyzed by TEM, FTIR, UV-Vis and XPS spectroscopy.

\section{Conjugation of temozolomide with gold nanostructures}

The simple method described below provides highly monodispersed GNP-L-aspartate nanostructures that are required as intermediates in the preparation of the target delivery vector, GNP-L-aspartate-TMZ. First, $200 \mu \mathrm{L}$ of temozolomide $(50 \mu \mathrm{L} / \mathrm{mL})$ was added to the GNP-L-aspartate nanostructure solution $(10 \mathrm{~mL}, 2 \mathrm{nM})$ and stirred for one hour. The resulting vector (GNP-L-aspartate-TMZ) was analyzed by TEM, FTIR, UV-Vis and XPS spectroscopy.

\section{Analytical characterization of multicomponent nanosystems}

The optical properties of the GNP-L-aspartate nanostructures and GNP-L-aspartate-TMZ vector were monitored using an ultraviolet visible spectrophotometer (JASCO V-570, Jasco Inc, Easton, MD). The morphology of the GNP-L-aspartate and GNP-L-aspartate-TMZ was investigated by TEM under conventional beam conditions. Next, $30 \mu \mathrm{L}$ droplets of suspension were pipetted on copper grids $(3 \mathrm{~mm}$ diameter, 300 meshes) previously covered with parlodion and carbon films. After 2 minutes, the liquid was absorbed with filter paper. Examination of the grids was performed using TEM (JEM 1010, JEOL, Tokyo, Japan). The images were captured using a Mega VIEW III camera (Olympus, Soft Imaging System, Münster, Germany) and entered into a database using Soft Imaging System software (Münster, Germany). The diameter of the nanoparticles was analyzed using CellD software (Olympus Soft Imaging Solutions GMBH). Statistical analyses (mean value, standard deviation, and Student's $t$-test) were performed using Microsoft Office Excel software (Microsoft Corporation, Redmond, WA, USA). Fourier transform infrared spectroscopy measurements were performed with a JASCO 6100 spectrometer in the $4000-500 \mathrm{~cm}^{-1}$ spectral region with a resolution of $4 \mathrm{~cm}^{-1}$ using the $\mathrm{KBr}$ pellet technique. $\mathrm{X}$-ray photoelectron spectroscopy associated with argon ion etching was used for qualitative and quantitative analysis of the nanocomposites using a SPECS custom-built system. Excitation was produced using the aluminum anode of the X-ray source $(h v=1486.6 \mathrm{eV})$.

\section{Cancer stem cells}

The gold standard assay to determine whether a stem cell is or is not a cancer stem cell involves a series of transplantations in animal models. Potential surface markers of cancer stem cells include CD133, aldehyde dehydrogenase 1, CD44, and CD24. Efflux of Hoechst or rhodamine dyes (also referred to as side populations) have also been employed for the identification of putative cancer stem cells. Still, these markers have significant limitations given the fact that they fail to identify all cancer stem cells and mostly recognize a cell subpopulation with increased clonogenic and tumorigenic activity. Moreover, not all cells presenting cancer stem cell marker phenotypes present the same behavior as the cancer stem cells. Most markers for the selection of cancer stem cells are chosen because of being expressed in normal stem cells and, most interestingly, there are quite a few molecules which are commonly expressed in both normal and cancer stem cells and which guide to various phenomena in dependency to the particular environment. ${ }^{24}$

The cancer stem cells used in this study were isolated from a glioblastoma multiforme biopsy as previously described. ${ }^{20}$ Briefly, after mechanical dissociation of the tumor tissue, the fragments were placed in $1 \mathrm{~mL}$ of fetal calf serum. After 3 hours, $3 \mathrm{~mL}$ of Dulbecco's modified Eagle's medium/F-12 medium supplemented with 15\% fetal calf serum was added to the dish. After reaching a subconfluent monolayer, the cells were detached using trypsinethylenediamine tetra-acetic acid (Merck) and resuspended in a serum-free medium, ie, Dulbecco's modified Eagle's medium/F-12 (1:1) medium supplemented with $15 \mathrm{ng} / \mathrm{mL}$ basic fibroblast growth factor, $20 \mathrm{ng} / \mathrm{mL}$ epidermal growth factor, $2 \mathrm{mM} / \mathrm{L}$ L-glutamine, $4 \mathrm{U} / \mathrm{L}$ insulin growth factor-1, and B-27 supplement 1:50 (Sigma Aldrich). Isolated and expanded cells revealed some stem cell-specific features, including expression of cellular markers (CD133, CD105, CD90, Nanog, Oct 3/4), immunocytochemistry expression of specific genes, ie, CXCR4, nestin, glial fibrillary acidic 
protein, and neurofilament protein (reverse transcriptase polymerase chain reaction). The cells also displayed a high proliferative potential despite chemotherapy and irradiation, and also had the ability to form spheroids in suspension.

All the studies were done by using exponentially growing cells with a doubling time of approximately 24 hours. For the passage, the medium was discarded and cells were washed with phosphate-buffered solution and afterwards detached with trypsin-ethylenediamine tetra-acetic acid $0.25 \%$.

\section{Proliferation assay}

Cancer stem cells isolated from a high-grade glioblastoma were cultivated in Dulbecco's modified Essential medium and Ham's F-12 (Dulbecco's modified Eagle's medium/ F-12, ratio 1:1) medium supplemented with $15 \%$ fetal calf serum, $100 \mathrm{U} / \mathrm{mL}$ penicillin, $100 \mu \mathrm{g} / \mathrm{mL}$ streptomycin, $1 \%$ nonessential amino acids, $2 \mathrm{mM}$ glutamine, $55 \mu \mathrm{M}$ beta-mercaptoethanol, and $1 \mathrm{mM}$ natrium pyruvate in a $37^{\circ} \mathrm{C}$ humidified incubator containing a mixture of $95 \%$ air and $5 \%$ carbon dioxide.

Cell survival was assessed using the 3-(4,5-dimethylthiazol-2-yl)-2,5-diphenyltetrazolium bromide (MTT) assay, for which cells in a monolayer culture were incubated in complete medium before being washed twice with phosphatebuffered solution. Cells were then incubated with trypsinethylenediamine tetra-acetic acid, resuspended in culture medium with fetal calf serum, counted, and plated in $100 \mu \mathrm{L}$ of medium at $15 \times 10^{3}$ cells/well in 96-well microtiter plates. After 24 hours, the cells were washed and treated with temozolomide alone or GNP-L-aspartate-TMZ. Temozolomide was added at a concentration of $5 \mu \mathrm{g} / \mathrm{mL}$. The MTT activity of the GNP-L-aspartate-TMZ was compared with that of temozolomide in identical concentrations. Absorbance of the MTT was measured at $492 \mathrm{~nm}$ using a fluorescence microplate reader (Synergy 2, BioTek, Winooski, VT, USA).

\section{Annexin V/propidium iodide staining apoptosis assay}

Glioblastoma-derived stem cells were cultivated at subconfluence in complete medium in $6 \mathrm{~cm}$ Petri dishes and were exposed for 24 hours to temozolomide at a concentration of $5 \mu \mathrm{g} / \mathrm{mL}$ or to GNP-L-aspartate-TMZ. The controls were untreated cells and cells treated with GNP-L-aspartate alone.

Apoptosis was evaluated using flow cytometry and optical microscopy by staining with a FITC Annexin V and propidium iodide kit (Invitrogen-Molecular Probes, Carlsbad, CA, USA). After 24 hours of drug exposure, the cells were harvested by trypsinization and washed with cold phosphate-buffered solution and then resuspended in $100 \mu \mathrm{L}$ of binding buffer. Next, $5 \mu \mathrm{L}$ of FITC Annexin V and $1 \mu \mathrm{L}$ of propidium iodide was added to each sample. The mixture was then incubated at room temperature in the dark for 15 minutes. Early and late apoptotic cells were identified using a BD FACSCanto ${ }^{\text {TM }}$ II flow cytometer (BD Biosciences, Franklin Lakes, NJ, USA) measuring fluorescence emission at $530 \mathrm{~nm}$ and $575 \mathrm{~nm}$ with $488 \mathrm{~nm}$ excitation. A similar protocol was used for staining adherent cells, and the samples were examined using an inverted phase microscope with a $488 \mathrm{~nm}$ fluorescence filter (Axiovert, Zeiss, Oberkochen, Germany). Image acquisition was performed using an AxioCam MRC camera, and cell counting of positive cells was performed using Axiovision Rel 4.6 image analysis software. Cells positive for Annexin V only are in an early stage of apoptosis, and cells positive for both Annexin $\mathrm{V}$ and propidium iodide are either dead or in a late stage of apoptosis.

\section{Statistical analysis}

Statistically significant values were obtained by using oneway variance analysis and a confidence level of $95 \%$ with a GraphPad Prism 5 statistics program (La Jolla, CA, USA). Data was analyzed with the Bonferroni multiple comparison test (Kruskal-Wallis as nonparametric). Statistical significance was set at $P<0.05$, and all experiments were performed in triplicate.

\section{Results and discussion Synthesis and characterization of GNP-L- aspartate-TMZ delivery vector}

Aspartate-stabilized gold nanoparticles were used for binding of temozolomide in order to form the desired final drug delivery system. Aspartate was used for reduction and stabilization in the synthesis of the nanostructures. Shape, size, and the surface ligand are important parameters with distinctive properties that must be chosen very carefully because they influence cellular binding, incorporation, and/or cytotoxicity. In order to establish the structure of the drug delivery system, we studied the conjugation of temozolomide with the GNP-Laspartate nanostructures. The binding of temozolomide to the surface of GNP-L-aspartate is an important parameter with a significant impact on the overall stability of the nanostructural multicomponent system.

First, the gold nanostructures were synthesized by reducing the gold salt, $\mathrm{HAuCl}_{4}$, in a strong acidic medium ( $\left.\mathrm{pH} 2\right)$ in the presence of L-aspartate molecules. Briefly, under continuous stirring, $0.25 \times 10^{-5}$ moles of $\mathrm{HAuCl}_{4}$ were 
reduced with $2.25 \times 10^{-4}$ moles of L-aspartate at room temperature for 24 hours. Mixed chlorohydroxo complexes $\left(\mathrm{AuCl}_{2} \mathrm{O}_{2}{ }^{-3}\right.$ or $\left.\mathrm{AuClO}_{3}{ }^{4-}\right)$ were present around the L-aspartate molecules. Nucleation of the gold atoms took place very slowly, with reduction occurring after 9 hours of reaction, and was evident visually by a change of color from pale yellow to pink to red violet. Triangular nanoparticles having a diameter of approximately $55 \mathrm{~nm}$ and aspartate as a ligand were synthesized by this method and used as a delivery vector for temozolomide. The resulting GNP-L-aspartate nanostructures were purified by centrifugation and used further in the reaction with temozolomide in order to obtain the desired compound, ie, GNP-L-aspartate. TEM (Figure 1A) and vibrational spectroscopy (Figure S1) were used to characterize the structures. Further, these nanostructures were used as building blocks for formation of the delivery vector, GNP-L-aspartate. Temozolomide was conjugated with GNP-L-aspartate by formation of electrostatic bonds between temozolomide and the aspartate molecules. Attachment was confirmed by TEM, vibrational spectroscopy, and $\mathrm{x}$-ray photoelectron spectroscopy. TEM analysis along with diameter histograms are shown in Figure 1A-C. The images confirmed formation of the nanostructures and their triangular shape. The length of the chains ranged from $100 \mathrm{~nm}$ to $600 \mathrm{~nm}$, with the majority in the range of $600 \mathrm{~nm}$, and a mean diameter of $55 \mathrm{~nm}$ (see Figure 1A). A typical image showing the drug delivery system is seen in Figure 1B. A thin shell of temozolomide was seen to cover the nanostructure surface. It is interesting to note that, after coupling, no secondary effects such as nanoparticle aggregation appeared even one year after
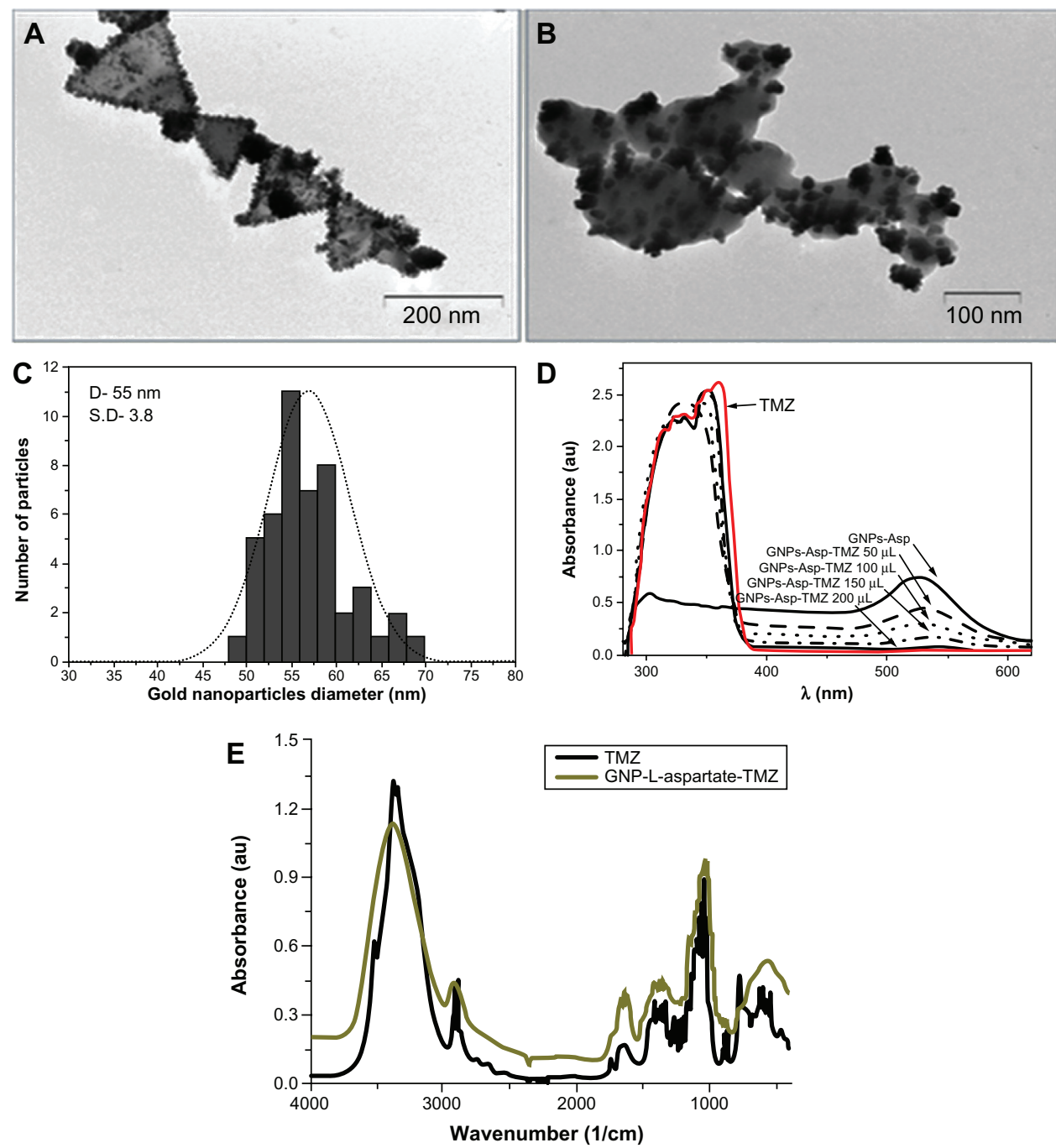

Figure I Transmission electron microscopic images of GNP-L-aspartate, showing a median diameter of $55 \mathrm{~nm}$ with a standard deviation of 3.8 (A), the GNP-L-aspartateTMZ delivery system (B), a representative size distribution histogram of the gold nanoparticles (C), an ultraviolet-visible absorption spectrum confirming adsorption of the drug into the nanostructure (D), and Fourier transform infrared spectra of (black) pure temozolomide and (green) GNP-L-aspartate-TMZ (E). Abbreviations: GNP, gold nanoparticles; TMZ, temozolomide. 
their preparation. The presence of temozolomide on the gold surfaces was also demonstrated by ultraviolet-visible spectroscopy (Figure 1D) and vibrational spectroscopy (Fourier transform infrared, Figure 1E).

Ultraviolet visible spectroscopy clearly showed absorption of the drug onto the surfaces of the nanostructure complexes. One peak at around $520 \mathrm{~nm}$ corresponds to the gold nanoparticles, and the other two at approximately $300 \mathrm{~nm}$ and $350 \mathrm{~nm}$ are attributed to aspartic acid and temozolomide, respectively. From the spectrum, we can also see that the drug absorbs to the nanostructure surface until equilibrium is reached. The quantity of drug that results in equilibrium is $200 \mu \mathrm{L}$ (Figure 1D).

The Fourier transform infrared spectrum for pure temozolomide has three broad bands at 3339, 3381, and $3526 \mathrm{~cm}^{-1}$ given by the stretching vibration modes of $\mathrm{NH}_{2}$ and $\mathrm{OH}^{-}$, while the two bands at around $2935 \mathrm{~cm}^{-1}$ and $2899 \mathrm{~cm}^{-1}$ are related to the stretching vibrations of the aliphatic methylene groups. After interaction with gold, two single bands appear in this region, with one at $3389 \mathrm{~cm}^{-1}$ from the stretching vibration of $\mathrm{NH}_{3}^{+}$groups and the other at $2934 \mathrm{~cm}^{-1}$ from the vibration of $\mathrm{C}-\mathrm{H}$ and $\mathrm{CH}_{3}$. This change is due to electrostatic interaction of these groups with the gold nanoparticles.

In the middle of the spectrum at $1746 \mathrm{~cm}^{-1}$ is a fourmember ring from the ketone band which is similar to that of pure temozolomide but more intense due to the presence of gold in the structure. The amide I is indirectly influenced by the $\mathrm{NH}_{2}$-nanostructure linkage and has a peak at $1682 \mathrm{~cm}^{-1}$, whereas in the pure temozolomide the peak appears at $1672 \mathrm{~cm}^{-1}$. There are no similarities between the Fourier transform infrared spectrum of pure temozolomide and that of the temozolomide-loaded gold nanoparticle sample (all peaks are rounded and shifted), suggesting that strong electrostatic interactions, such as hydrogen bonds, Van der Waals forces, or other mechanical or halogen bonds, can occur between temozolomide molecules and gold nanostructures.

$\mathrm{X}$-ray photoelectron spectroscopic analysis was utilized to clarify the binding of temozolomide to the gold surface by studying the N $1 s$ and Au $4 f$ core-level lines. The deconvoluted $\mathrm{x}$-ray photoelectron spectroscopic lines of $\mathrm{N} 1 s$ core-level 1 for the GNP-L-aspartate sample are presented in Figure 2A, while Figure 2B shows the deconvolution lines of $\mathrm{Au} 4 f$ core-levels. For GNP-L-aspartate, the recorded $\mathrm{x}$-ray photoelectron spectroscopic spectrum of $\mathrm{N} 1 s$ core-level deconvoluted peaks and their assignment are shown in Figure 2C, while the corresponding $\mathrm{Au} 4 f$ core-level deconvoluted doublet peaks are shown in Figure 2D.
The following lines are identifiable in Figure 2A: a deprotonated $\mathrm{N}$ of the amine group bound (attached) to the gold surface at $396.52 \mathrm{eV}$; an unattached $\mathrm{N}$ of the amine group at $401.67 \mathrm{eV}$; and a deprotonated positive $\mathrm{N}$ (not bound) at $402.88 \mathrm{eV}^{25,26}$ Peak positions, line widths, and quantified area are summarized in Table S1.

Quantification of the data was done by taking into account real sensitivity, transmission, and mean free path factors. The molar ratio of aspartic acid to gold nanoparticles was found to be 0.22 by taking into account the attenuation lengths for L-aspartic acid (about $2.1 \mathrm{~nm}$ ) and gold nanoparticles $(1 \mathrm{~nm})$. These values were calculated following the method of Cumpson and Seah. ${ }^{27}$ The X-ray photoelectron spectra for GNP-L-aspartate-TMZ are presented in Figure 2C and D for $\mathrm{N}$ $1 s$ core-level 1 and $\mathrm{Au} 4 f$ core-levels, respectively. Comparing the X-ray photoelectron spectrum of the $\mathrm{N} 1 s$ core-level from GNP-L-aspartate (Figure 2A) with the corresponding $\mathrm{X}$-ray photoelectron spectrum from GNP-L-aspartate-TMZ (Figure 2C), we can see that the intensities of the peaks and the positions of the spectra have changed. These data led us to conclude that the drug had bound to the surface of the nanostructured gold by forming electrostatic bonds.

The molar ratio value obtained for GNP-L-aspartateTMZ was found to be 0.047 . For its calculation, we took into consideration the molar ratio value of aspartic acid to gold nanoparticles $(0.22)$ and the integrated intensity values. We also used the lengths corresponding to the total integrated intensity of $\mathrm{Au} 4 f$ and $\mathrm{N} 1 s$.

\section{Testing efficacy of GNP-L-aspartate-TMZ in glioblastoma stem cells}

The resemblances of the self-renewal mechanisms of the cancer and stem cells, have resulted in the new concept of cancer stem cells. Over the course of the past 15 years, there has been increasing evidence to support the hypothesis of cancer stem cells, which indicates that these cells might be responsible for initiation, of tumors, metastasis, and their complex resistance to treatment. Therefore, it could be possible that a tumor might have its origins in the cancer stem cells, which could be originated from modified stem cells or progenitor cells with re-obtained self-renewal activity. ${ }^{28}$ These rare cancer stem cells could play a major role in the control and treatment of this disease: due to asymmetric division, tumor development along with evade therapy given the characteristics shared by normal stem cells, that include quiescence, self-renewal capacity, and drug resistance through complex pump activity. ${ }^{29}$ These cells were first identified in hematologic cancers, but have been recently isolated from 

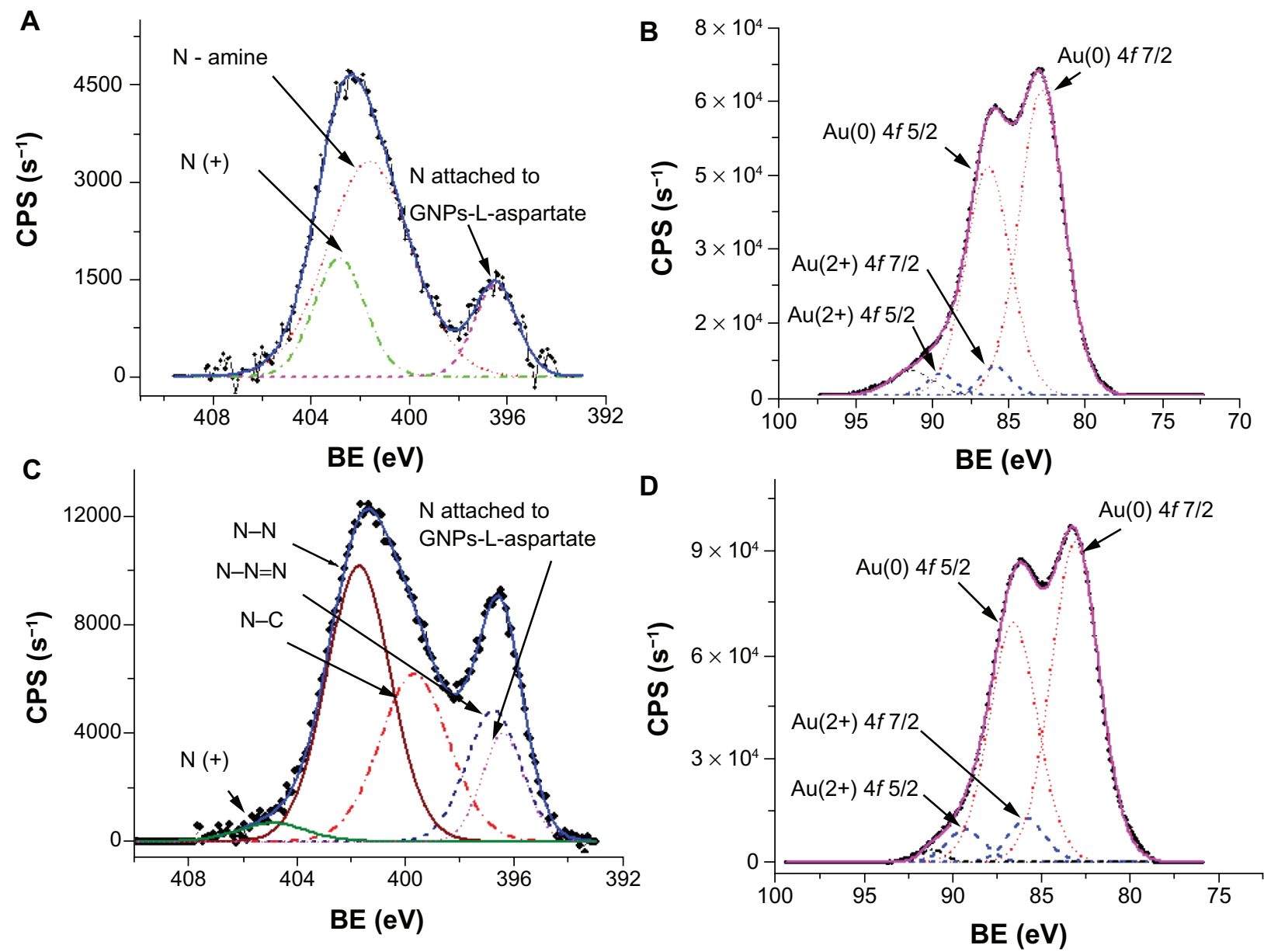

Figure 2 X-ray photoelectron spectra of GNP-L-aspartate and GNP-L-aspartate-TMZ delivery systems. (A) X-ray photoelectron spectrum of N Is core-level for GNPL-aspartate together with the corresponding deconvoluted peaks and their assignment. The continuous line represents the calculated envelope. (B) X-ray photoelectron spectrum of $\mathrm{Au} 4 f$ core-level for GNP-L-aspartate together with the corresponding deconvoluted doublet peaks. $A u(0)$ and $A u(2+) 4 f$ doublet peaks are evident. The continuous line represents the calculated envelope. An additional unknown line appears at $91.39 \mathrm{eV}$, which could be seen as a "ghost" line due to presence of plasmon modes at the surface of Au nanoparticles. ${ }^{25}$ (C) X-ray photoelectron spectrum of N Is core-level for GNP-L-aspartate-TMZ, together with the corresponding deconvoluted peaks and their assignment. The continuous line represents the calculated envelope. (D) X-ray photoelectron spectrum of Au $4 f$ core-level for GNP-L-aspartate-TMZ, together with the corresponding deconvoluted doublet peaks. The continuous line represents the calculated envelope.

Abbreviations: CPS, counts-per-second; BE, binding energies; GNP, gold nanoparticles; TMZ, temozolomide.

solid tumors. Cancer stem cells are tumor-initiating cells in immunocompromised mice, and have the ability to generate heterogeneous cancer cell populations. ${ }^{30,31}$

Based on these considerations, our goal was to use the properties of nanomaterials to evade activation of the complex self-renewal mechanism in cancer stem cells. Our study revealed that, by using conjugated nanomaterials, the rate of cell killing can be increased by up to $50 \%$ compared with the rate achieved by the anticancer drug alone. Our new synthesized GNP-L-aspartate compound was incubated for 24 hours with glioblastoma stem cells in vitro. In parallel, temozolomide was also incubated with a second cell line for use as a control. After 24 hours of internalization, we noticed that the GNP-L-aspartate-TMZ induced preapoptosis, leading to cell death. The number of viable cells decreased dramatically when exposed to GNP-L-aspartate-TMZ in comparison with exposure to the drug alone. The mechanism of uptake of the system into glioblastoma stem cells and their destruction is depicted in Figure 3.

\section{MTT cytotoxicity assay}

The interaction between gold nanoparticles and various cancer cell lines has been intensively studied, but very little is known about how these nanomaterials interact with derived stem cells. Generally, gold nanoparticles have been reported to have good biocompatibility with nonstem cells, but with effects dependent upon the particular cell line used in the experiment. ${ }^{32-34}$ Moreover, the surface chemistry, ${ }^{35}$ size, ${ }^{35}$ and concentration have been shown to affect the internalization mechanism for such nanomaterials. ${ }^{36}$

The surface modifiers used to stabilize gold nanoparticles include a range of anionic, cationic, and neutral groups, such 


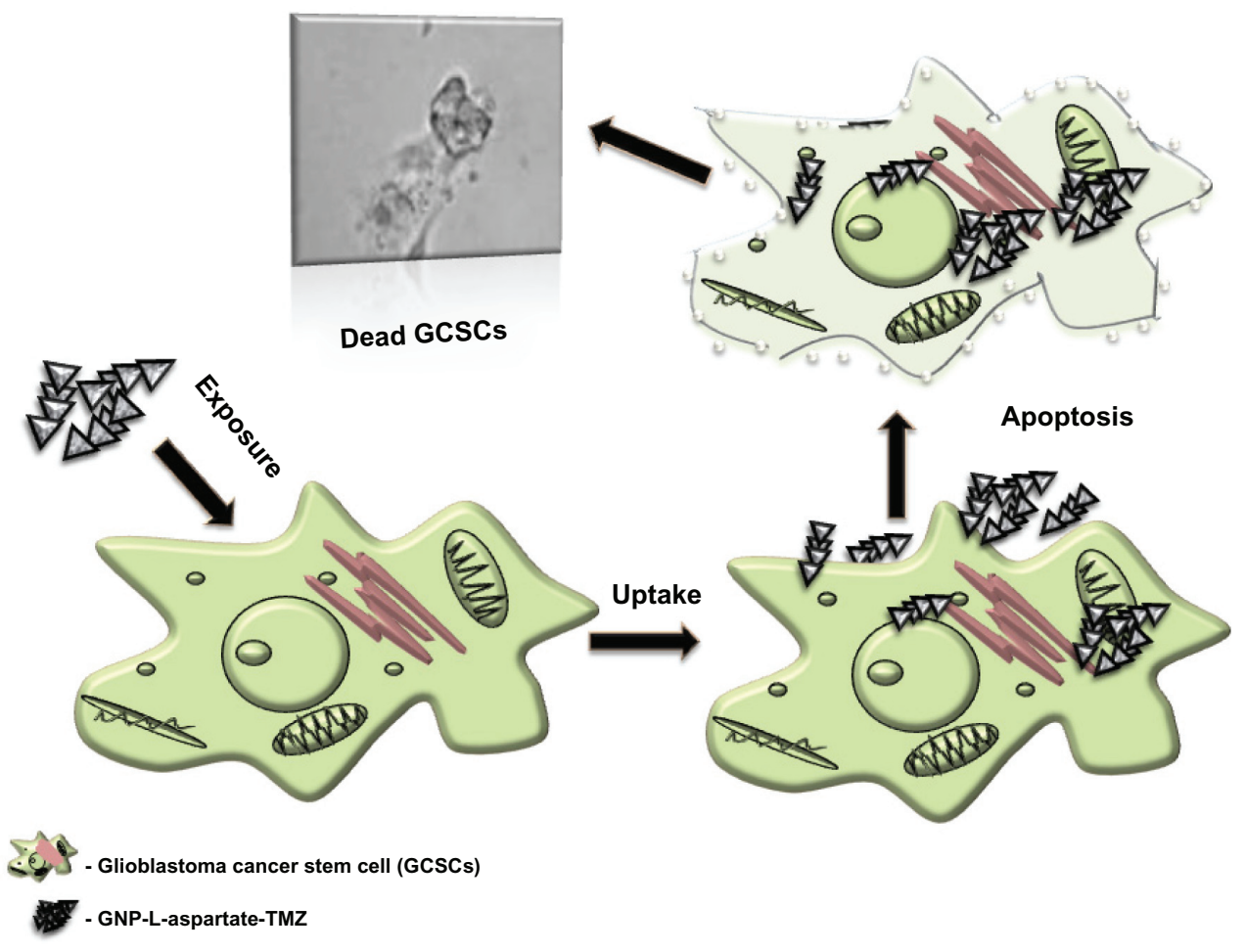

Figure 3 Drug delivery system uptake and cancer cell destruction. Abbreviations: GNP, gold nanoparticles; TMZ, temozolomide.

as citrate, amine, and glucose. Thus, it has been concluded that the interaction depends upon how the biological cells respond to foreign materials in general, ie, the basic mechanism of incorporation, degradation, or bioaccumulation causing cell damage and changes in gene expression. ${ }^{37,38}$

A very common method of evaluating the effects of different substances in cell cultures is the MTT assay, which is used to measure the mitochondrial function of cells in vitro (Figure 4A). Herein, glioma cancer stem cells were found to interact strongly with our gold nanoparticle-based drug delivery vectors. Phase contrast microscopy showed that GNP-L-aspartate was internalized within the first hour (data not shown here). After 24 hours, the drug delivery vector affected the number of cells, their rate of proliferation, and their shape, suggesting that the cells entered a preapoptotic stage, as shown in Figure 4B. Hence, cells cultivated in the presence of the nonconjugated drug were not yet preapoptotic (Figure 4C). Glioma-derived stem cells were initially resistant to temozolomide but, when GNP-L-aspartate-TMZ was added to the culture medium, the results showed a reduction in the rate of survival of the tumor cells.

Using Bonferroni's multiple comparison test, we found statistically significant $(P<0.05)$ decrease in proliferation for cells treated with the conjugated vector, GNP-L-aspartateTMZ, compared with the cells treated with TMZ alone (95\% confidence interval 0.09214-0.5345). The killing efficiency of the GNP-L-aspartate-TMZ system in glioblastoma-derived stem cells is approximately $50 \%$ higher compared with that of the alkaline drug, temozolomide, used alone. When one or several initiating genetic changes appeared at the progenitor level, all of the downstream cells continued this change. In one particular case, it is possible that a daughter cell acquired not only the characteristics of the stem cell, but also underwent additional alterations that allowed the glioma to progress further and invade adjacent tissues. Due to their small population of glioblastoma-derived stem cells, malignant gliomas have a negative response to various conventional treatments. ${ }^{39}$

\section{Flow cytometry apoptosis test}

Annexin $\mathrm{V}$ binding to the cell membrane by conjugation of FITC was measured to identify and quantify apoptotic cells at the single-cell level by flow cytometry or fluorescence microscopy. Staining cells simultaneously with FITCAnnexin V (green fluorescence) and the nonvital dye, propidium iodide (red fluorescence) enables (bivariate analysis) to distinguish between intact cells (FITC negative, propidium iodide negative), early apoptotic (FITC positive, propidium iodide negative), and late apoptotic or necrotic cells (FITC positive, propidium iodide positive). We performed the apoptotic tests using the flow cytometry method and fluorescence microscopy. 

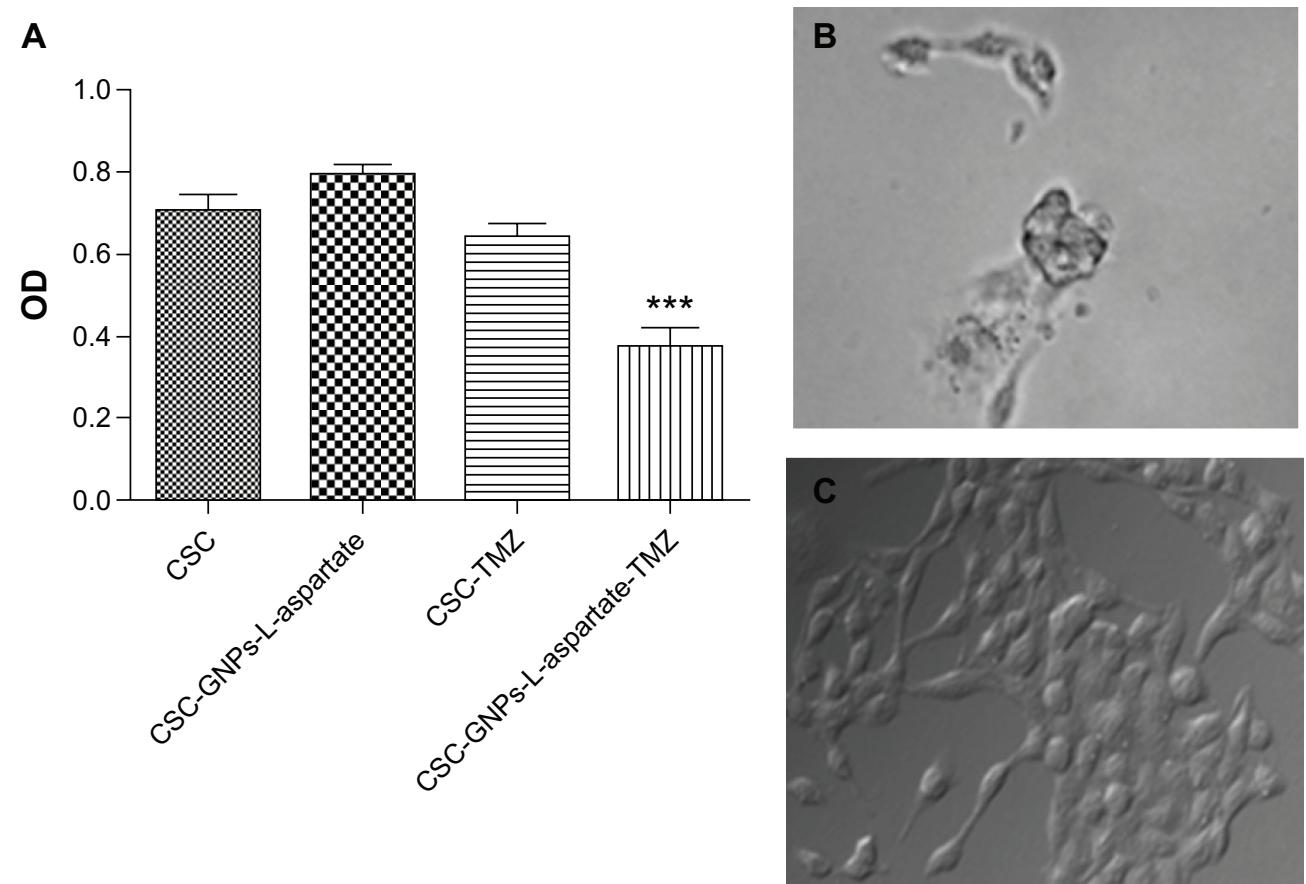

Figure 4 MTT viability assay results showing the response of glioma-derived stem cells to GNP-L-aspartate, to temozolomide, and to GNP-L-aspartate-TMZ. (A) Typical preapoptotic cell after 24 hours of incubation with GNP-L-aspartate-TMZ (PlasDIC phase contrast, magnification 400×), (B) in comparison with control cells treated with temozolomide alone, and $(\mathbf{C})$ control cells cultured without GNP-L-aspartate-TMZ (white light microscopy, PlasDIC contrast phase, magnification 400X).

Abbreviations: CSC, cancer stem cells; GNPs, gold nanoparticles; TMZ, temozolomide.

Analyzing the results of the flow cytometry apoptosis assay, we observed a slight increase in apoptosis among cells treated with gold nanoparticles (apoptotic cells represent $10.7 \%$ of total cells by comparison with the level of $0.8 \%$ found in control cells), a fact that was not found in the microscopy apoptosis test $(0.9 \%$ versus $1.24 \%$ for control cells). This observation might be explained by the mechanical stress affecting the cells loaded with nanoparticles during the centrifugation step for the flow cytometry method, a step which was not included in the microscopy test. Both apoptosis tests revealed an increase in apoptosis among cells exposed to gold nanoparticles conjugated with temozolomide. We noticed a dramatic enhancement of late apoptosis in the flow cytometry studies by $78.3 \%$, represents a 1.9-fold increase within 24 hours compared with the rate of apoptosis in cells treated with temozolomide alone (31.1\%). Similar results were obtained for the microscopic analysis, with the observation that the apoptotic index of cells treated with temozolomide-conjugated with gold nanoparticles was 3.41 times higher than that of cells treated with temozolomide alone (Table 1).

Treatment with GNP-L-aspartate-TMZ induced translocation of plasma membrane phosphatidylserine as an early apoptosis event in cancer stem cells, and binding of Annexin V-FITC was visualized by fluorescence microscopy as shown in Figure 5. However, these cells retained a morphology and proliferation rate close to that observed in the control group. GNP-conjugated temozolomide-treated cells showed positivity for Annexin V-FITC, a rounded shape, and a decrease in cell numbers and adhesion (see Figure 5).

Our proposed nanoscale drug delivery system offers a promising chemotherapeutic strategy for patients diagnosed with unresectable recurrent malignant glioma. Current therapies are not yet curative, because cancer stem cells may survive as a result of the increased efflux of chemotherapy agents due to ABCG2 cell membrane proteins and enhanced DNA repair. ${ }^{40}$ Multiple proteins of the ATP-binding cassette superfamily are being overexpressed by the cancer stem cells

Table I Comparison of double staining with Annexin V/propidium iodide obtained by flow cytometry: percentage of early, late, and total apoptotic glioblastoma-derived cancer stem cells

\begin{tabular}{llll}
\hline Sample & $\begin{array}{l}\text { \% early } \\
\text { apoptotic cells }\end{array}$ & $\begin{array}{l}\text { \% late apoptotic + } \\
\text { dead cells }\end{array}$ & Total \\
\hline CSC control & 0.4 & 0.4 & 0.8 \\
$\begin{array}{l}\text { CSC control with } \\
\text { GNP-L-aspartate }\end{array}$ & 6.6 & 4.1 & 10.7 \\
$\begin{array}{l}\text { CSC treated with } \\
\text { temozolomide }\end{array}$ & 10.8 & 31.1 & 41.9 \\
$\begin{array}{l}\text { CSC treated with } \\
\text { GNP-L-aspartate-TMZ }\end{array}$ & 4.4 & 78.3 & 82.7 \\
\hline
\end{tabular}

Abbreviations: CSC, cancer stem cells; GNP, gold nanoparticles; TMZ, temozolomide. 

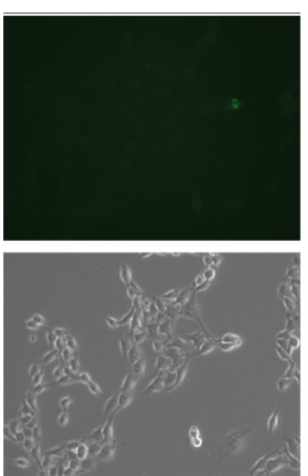

Control
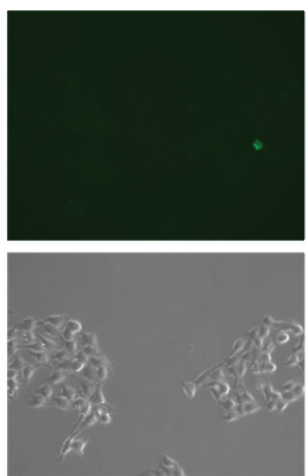

Control GNP
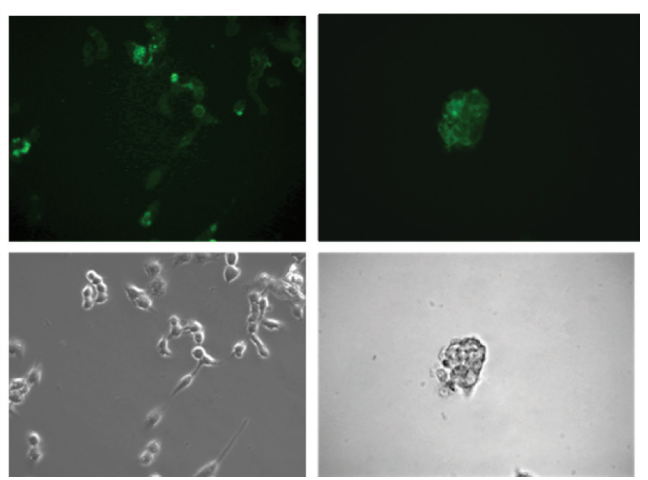

TMZ

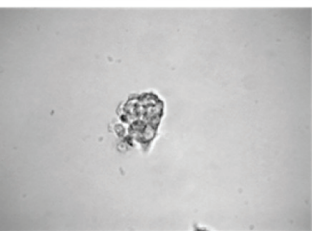

GNP-TMZ

Figure 5 Morphologic aspects of cellular apoptosis studies for Annexin V FITC/propidium iodide staining observed in contrast phase and fluorescent microscopy (magnification 400 $\times$ ).

Note: The upper panel shows images in fluorescence corresponding to those obtained in white light microscopy (lower panel).

Abbreviations: GNP, gold nanoparticles; TMZ, temozolomide.

and produce a side population, with the capacity for enhanced efflux of the fluorescent dyes (Hoechst 33342 or rhodamine 123) and which are transported by the same $A B C$ family proteins..$^{41}$ Because therapy-resistant, high-grade gliomas are one of the common causes of death due to cancer, and as a result, there is an urgent need for identification of alternative targeted and more efficient therapies. Such is the case with specific drug-delivery systems using nanoparticles. Further combination of various approaches to killing of individual cancer cells, such as photothermolysis ${ }^{42,43}$ and radiofrequency-induced heating, ${ }^{44,45}$ which combine more accurate drug release with additional biological damage produced by heated nanomaterials, could further increase the ability of nanostructured materials to serve as the foundation for more sophisticated approaches to cancer treatment.

\section{Conclusion}

Cancer cells are very complex biological structures that perform a variety of functions, ranging from invasion or metastasis to elimination of anticancer drugs from the cell membrane. Although the exact mechanisms need to be explored further, combining advances in fundamental oncology and nanotechnology offers the opportunity to impact future diagnostics and therapeutics in a significant way. We have shown that drug delivery vectors based on gold nanoparticles have the ability to deliver temozolomide, a cytostatic drug, to treat unresectable recurrent malignant glioma. Our studies have also shown that a novel drug delivery vector based on gold nanoparticles has low toxicity and the ability to internalize temozolomide. MTT and flow cytometry studies have clearly indicated the high bioactivity of the GNP-L-aspartate-TMZ nanostructure system, with the ability to induce apoptosis in almost $90 \%$ of high-grade glioma-derived cancer stem cells. Temozolomide alone induced death in only $42 \%$ of the cells. Our results indicate synergistic enhancement of the apoptosis-inducing activity of GNP-L-aspartate-TMZ vectors compared with GNP-L-aspartate or temozolomide alone. This approach could constitute a novel method for treating incurable recurrent malignant gliomas, and could be developed further for other types of cancer models, and potentially with great success.

\section{Acknowledgments}

This research was supported by a grant from the Romanian Ministry of Research and Education (contract ID 1161). ASB acknowledges the financial support of the US Army Telemedicine and Advanced Technology Research Center program. The editorial assistance of Marinelle Ringer is also acknowledged.

\section{Disclosure}

The authors report no conflicts of interest in this work.

\section{References}

1. Shapiro WR, Shapiro JR. Biology and treatment of malignant glioma. Oncology. 1998;12:233-240.

2. Henke G, Paulsen F, Steinbach JP, et al. Hypofractionated reirradiation for recurrent malignant glioma. Strahlenther Onkol. 2009;185:113-119. German.

3. Buie LW, Valgus JM. Current treatment options for the management of glioblastoma multiforme. Hematol Oncol Pharm. 2012;2:57-63.

4. Eyler CE, Rich JN. Survival of the fittest: cancer stem cells in therapeutic resistance and angiogenesis. J Clin Oncol. 2008;26:2839-2845.

5. Li X, Lewis MT, Huang J, et al. Intrinsic resistance of tumorigenic breast cancer cells to chemotherapy. J Natl Cancer Inst. 2008;100:672-679.

6. Diehn M, Cho RW, Lobo NA, et al. Association of reactive oxygen species levels and radioresistance in cancer stem cells. Nature. 2009;458: 780-783.

7. De Jong WH, Hagens WI, Krystek P, Burger MC, Sips AJ, Geertsma RE. Particle size-dependent organ distribution of gold nanoparticles after intravenous administration. Biomaterials. 2008;29:1912-1919. 
8. Sonavane G, Tomoda K, Makino K. Biodistribution of colloidal gold nanoparticles after intravenous administration: effect of particle size. Colloids Surf B Biointerfaces. 2008;66:274-280.

9. Huang X, Jain PK, El-Sayed IH, El-Sayed MA. Gold nanoparticles: interesting optical properties and recent applications in cancer diagnostics and therapy. Nanomedicine (Lond). 2007;2:681-693.

10. Kim BYS, Rutka JT, Chan WCW. Nanomedicine. $N$ Engl J Med. 2010;363:2434-2443.

11. Lammers T, Subr V, Ulbrich K, et al. HPMA-based polymer therapeutics improve the efficacy of surgery, of radiotherapy and of chemotherapy combinations. Nanomedicine (Lond). 2010;5:1501-1523.

12. Grimm J, Scheinberg DA. Will nanotechnology influence targeted cancer therapy? Semin Radiat Oncol. 2011;21:80-87.

13. Dharap SS, Wang Y, Chandna P, et al. Tumor-specific targeting of an anticancer drug delivery system by LHRH peptide. Proc Natl Acad Sci US A. 2005;102:12962-12967.

14. Han G, Ghosh P, Rotello VM. Functionalized gold nanoparticles for drug delivery. Nanomedicine. 2007;2:113-123.

15. Liong M, Lu J, Kovochich M, et al. Multifunctional inorganic nanoparticles for imaging, targeting, and drug delivery. ACS Nano. 2008;2: 889-896.

16. Khan JA, Kudgus RA, Szabolcs A, et al. Designing nanoconjugates to effectively target pancreatic cancer cells in vitro and in vivo. PLoS One. 2011;6:e20347.

17. Chen YH, Tsai CY, Huang PY, et al. Methotrexate conjugated to gold nanoparticles inhibits tumor growth in a syngeneic lung tumor model. Mol Pharm. 2007;4:713-722.

18. Patra CR, Bhattacharya R, Wang E, et al. Targeted delivery of gemcitabine to pancreatic adenocarcinoma using cetuximab as a targeting agent. Cancer Res. 2008;68:1970-1978.

19. Liu C-J. Enhanced x-ray irradiation-induced cancer cell damage by gold nanoparticles treated by a new synthesis method of polyethylene glycol modification. Nanotechnology. 2008;19:295104.

20. Tomuleasa C, Soritau O, Rus-Ciuca D, et al. Functional and molecular characterization of glioblastoma multiforme derived cancer stem cells. J BUON. 2010;15:583-591.

21. Torcuator RG, Thind R, Patel M, et al. The role of salvage reirradiation for malignant gliomas that progress on bevacizumab. Neurooncol. 2010;97(3):401-407.

22. Stupp R, Mason WP, van den Bent MJ, et al. European Organisation for Research and Treatment of Cancer Brain Tumor and Radiotherapy Groups, National Cancer Institute of Canada Clinical Trials Group. Radiotherapy plus concomitant and adjuvant temozolomide for glioblastoma. N Engl J Med. 2005;352:987-996.

23. Kora AJ, Beedu SR, Jayaraman A. Size-controlled green synthesis of silver nanoparticles mediated by gum ghatti (Anogeissus latifolia) and its biological activity. Org Med Chem Lett. 2012;2:17.

24. Iwasaki H, Suda T. Cancer stem cells and their niche. Cancer Sci. 2009;100:1166-1172.

25. Leiro J, Minni E, Suoninen E. Study of plasmon structure in XPS spectra of silver and gold. J Phys F Met Phys. 1983;13:215-221.

26. Kang ET, Neoh KG, Tan KL. X-ray photoelectron spectroscopic studies of electroactive polymers advances. Polymer Science. 1993;106 135-190.

27. Cumpson PJ, Seah MP. Elastic scattering corrections in AES and XPS. II. Estimating attenuation lengths and conditions required for their valid use in overlayer/substrate experiments. Surf Interface Anal. 1997;25:430-446.
28. Dittmar T, Nagler C, Schwitalla S, Reith G, Niggemann B, Zänker KS. Recurrence cancer stem cells - made by cell fusion? Med Hypotheses. 2009; 73:542-547.

29. Fabian A, Barok M, Vereb G, Szollosi J. Die hard: are cancer stem cells the Bruce Willises of tumor biology? Cytometry A. 2009;75A: $67-74$.

30. Keysar SB, Jimeno A. More than markers: biological significance of cancer stem cell-defining molecules. Mol Cancer Ther. 2010;9: 92450-92457.

31. Butterworth K, McMahon S, Currell F, Prise M. Physical basis and biological mechanisms of gold nanoparticle radiosensitization. Nanoscale. 2012;4:4830-4838.

32. Orza A, Soritau O, Olenic L, et al. Electrically conductive goldcoated collagen nanofibers for placental-derived mesenchymal stem cells enhanced differentiation and proliferation. ACS Nano. 2011;5: 4490-4500.

33. Sathuluri RR, Yoshikawa H, Shimizu E, Saito M, Tamiya E. Gold nanoparticle-based surface-enhanced Raman scattering for noninvasive molecular probing of embryonic stem cell differentiation. PLoS One. 2011;6:e22802.

34. Ricles LM, Nam SY, Sokolov K, Emelianov SY, Suggs LJ. Function of mesenchymal stem cells following loading of gold nanotracers. Int J Nanomedicine. 2011;6:407-416.

35. Wang Y, Wang Y, Wang L, Che Y, Li Z, Kong D. Preparation and evaluation of magnetic nanoparticles for cell labeling. J Nanosci Nanotechnol. 2011;11:3749-3756.

36. Nativo P, Prior IA, Brust M. Uptake and intracellular fate of surfacemodified gold nanoparticles. ACS Nano. 2008;2:1639-1644.

37. Maurer-Jones MA, Bantz KC, Love SA, Marquis BJ, Haynes CL. Toxicity of therapeutic nanoparticles. Nanomedicine. 2009;4:219-241.

38. Zhang Y, Xu Y, Li Z, et al. Mechanistic toxicity evaluation of pristine and PEGylated single-walled carbon nanotubes in neuronal PC12 cells. ACS Nano. 2011;5:7020-7033.

39. Florian IS, Tomuleasa C, Soritau O, et al. Cancer stem cells and malignant gliomas. From pathophysiology to targeted molecular therapy. J BUON. 2011;16:16-23.

40. Frosina G. DNA repair and resistance of gliomas to chemotherapy and radiotherapy. Mol Cancer Res. 2009;7:989-999.

41. Baguley BC. Multidrug resistance in cancer. Methods Mol Biol. 2010;596:1-14.

42. Huang X, Kang B, Qian W, et al. Comparative study of photothermolysis of cancer cells with nuclear-targeted or cytoplasm-targeted gold nanospheres: continuous wave or pulsed lasers. J Biomed Opt. 2010;15: 058002.

43. Zharov VP, Galitovsky V, Viegas, M. Photothermal detection of local thermal effects during selective nanophotothermolysis. Appl Phys Lett. 2003;83:4897-4899.

44. Kruse DE, Stephens DN, Lindfors HA, Ingham ES, Paoli EE, Ferrara KW. A radio-frequency coupling network for heating of citratecoated gold nanoparticles for cancer therapy: design and analysis. IEEE Trans Biomed Eng. 2011;58:2002-2012.

45. Maksimova IL, Akchurin GG, Khlebtsov BN, et al. Near-infrared laser photothermal therapy of cancer by using gold nanoparticles: computer simulations and experiment. Med Laser Appl. 2007;22:199-206.

46. Porter MD, Bright TB, Allara DL, Chidsey CE. Spontaneously organized molecular assemblies. 4. Structural characterization of $\mathrm{N}$-alkyl thiol monolayers on gold by optical ellipsometry, infrared spectroscopy, and electrochemistry. J Am Chem Soc. 1987;109:3559-3568. 


\section{Supplementary information}

Fourier transform infrared spectra

of pure temozolomide versus GNP-Laspartate and GNP-L-aspartate-TMZ

The $\mathrm{C}-\mathrm{H}$ stretching vibration groups at around $2750 \mathrm{~cm}^{-1}$ disappear when the drug is coupled with the nanostructures, and only one peak appears in the spectra. This explains the interaction of the drug with the gold surface. This is due to the chain length of the amino acids and its molecules which have a parallel orientation on the gold surface. These molecules pack into densities sufficient to form high-quality barriers for both electron and ion transfer processes. ${ }^{46}$ Also, from the other regions of the Fourier transform infrared spectra, it is clear that the drug is linked directly to the gold surface. We are not denying the existence of aspartic acid in the molecules because there may be some interaction. Please see the other two regions of the Fourier transform infrared spectra (Figure S1A-C).

\section{Fourier transform infrared spectra of GNP-L-aspartate vector}

In the middle of the spectrum $\left(2000 \mathrm{~cm}^{-1}\right)$, we can see only a shoulder that could be related to a carbonyl group, the bending
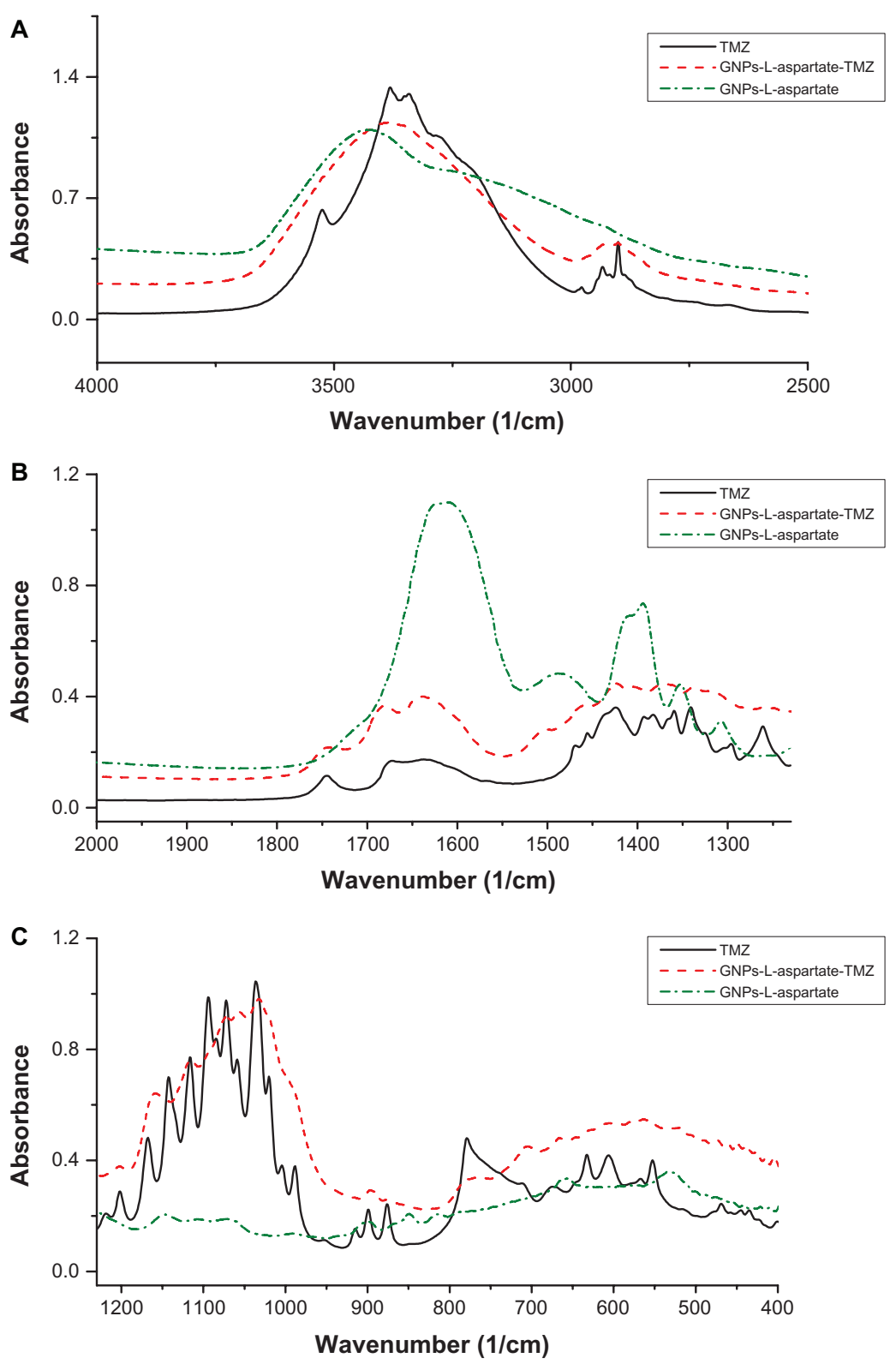

Figure SI Fourier transform infrared spectra of the pure temozolomide (black), GNP-L-aspartate (green) and GNP-L-aspartate-TMZ (red) region. (A) $4000-2500 \mathrm{~cm}^{-1}$ region, (B) $2000-1300 \mathrm{~cm}^{-1}$ region, and (C) $1200-400 \mathrm{~cm}^{-1}$ region.

Abbreviations: GNP, gold nanoparticles; TMZ, temozolomide. 
vibration of water at approximately $1650 \mathrm{~cm}^{-1}$, and the amide and $\mathrm{C}-\mathrm{C}$ double bond around $1500 \mathrm{~cm}^{-1}$. These peaks are shifted to the right and their height is smaller compared with the pure amino acid. The bending deformation vibrations of $\mathrm{C}-\mathrm{H}$ (methyl group) are given by a very weak peak at $1425 \mathrm{~cm}^{-1}$ (again because of their orientation parallel to the gold surface). As can be seen in Figure S2A and B, there is no similarity between the infrared spectrum of pure amino acid and the one that is bound to the gold nanoparticle surface on the gold nanoparticle-amino acid sample, suggesting that the L-aspartate is bound to the surface of the gold nanoparticles, most likely through the amino groups from the molecule.
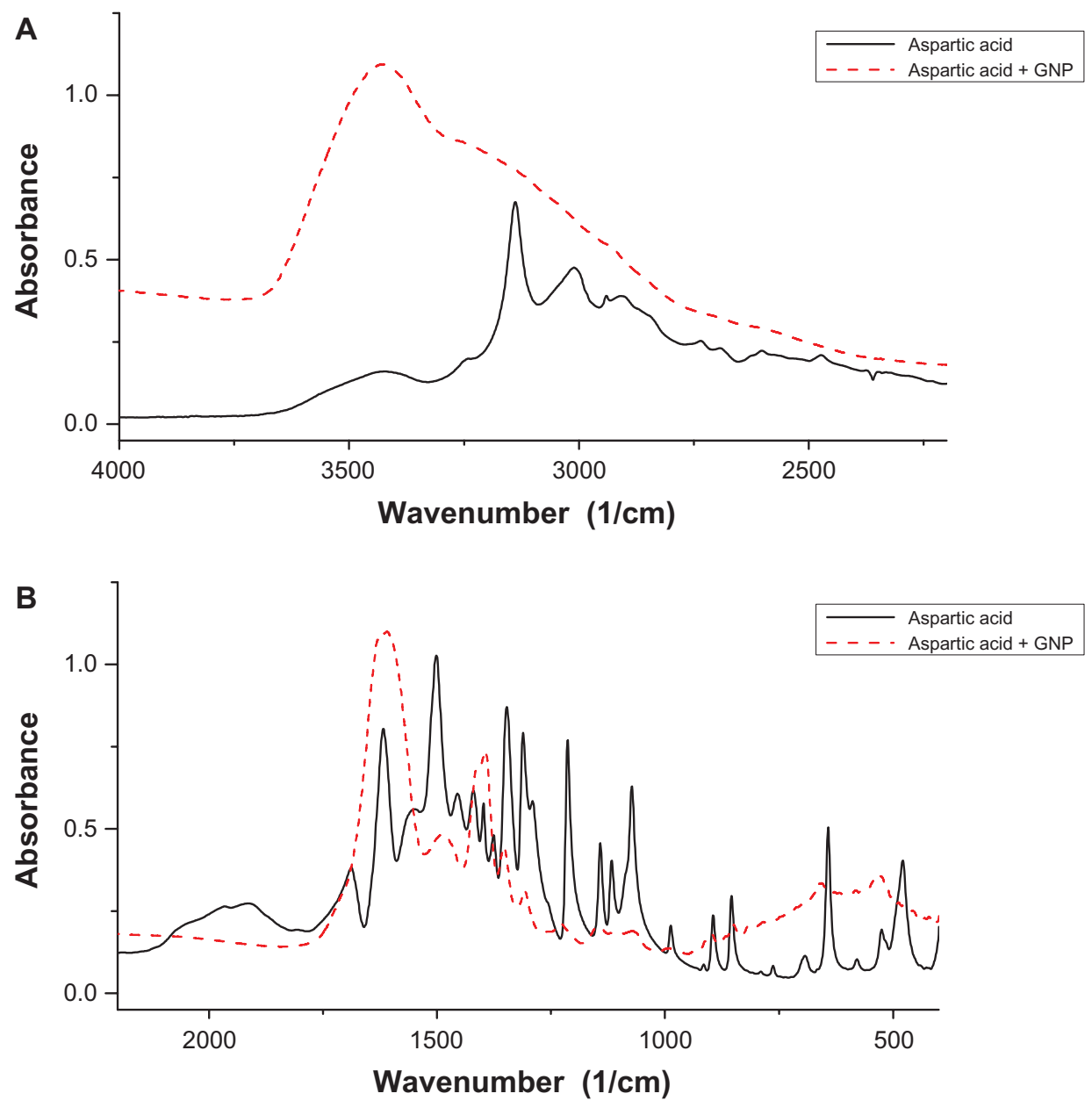

Figure S2 Fourier transform infrared spectra of (black) pure L-aspartate, (red) GNP-L-aspartate. (A) $4000-2500 \mathrm{~cm}^{-1} \mathrm{region}$ and (B) $2000-500 \mathrm{~cm}^{-1}$ region. 


\section{Table S I}

\begin{tabular}{|c|c|c|c|}
\hline Name & BE $(\mathrm{eV})$ & FWHM (eV) & Area (cps eV) \\
\hline \multicolumn{4}{|l|}{ GNP-L-aspartate } \\
\hline $\mathrm{N}$ Is-attached to Au & 396.53 & $\mathrm{I} .80 \mathrm{I}$ & 308.555 \\
\hline N Is-amine & 401.5 & 3.954 & 1415.19 \\
\hline $\mathrm{N}$ (deprotoned) Is & 402.8 & 2.683 & 833.197 \\
\hline$A u(0) 4 f 7 / 2$ & 82.89 & 3.436 & 4919.83 \\
\hline $\mathrm{Au}(0) 4 \mathrm{f} 5 / 2$ & 86.39 & 3.436 & 4691.03 \\
\hline $\mathrm{Au}(2+) 4 f \mathrm{f} / 2$ & 85.99 & 2.334 & 323.185 \\
\hline $\mathrm{Au}(2+) 4 f 5 / 2$ & 89.49 & 2.334 & 308.156 \\
\hline Unknown & 91.39 & 3.409 & \\
\hline \multicolumn{4}{|c|}{ GNP-L-aspartate-TMZ } \\
\hline $\mathrm{N}$ Is attached to $\mathrm{Au}$ & 396.41 & 1.843 & 958.012 \\
\hline $\mathrm{N}$ Is $\mathrm{N}-\mathrm{N}=\mathrm{N}$ imide & 396.78 & 2.34 & 1472.74 \\
\hline $\mathrm{N}$ Is N-C & 399.7 & 2.991 & 2410.35 \\
\hline $\mathrm{N}$ Is N-N & 401.76 & 2.794 & 3695.92 \\
\hline $\mathrm{N}$ Is (deprotoned) & 404.95 & 2.999 & 267.455 \\
\hline $\mathrm{Au} 4 \mathrm{f}(0) 7 / 2$ & 83.06 & 3.146 & 6637.89 \\
\hline$A u 4 f(0) 5 / 2$ & 86.56 & 3.146 & 6329.2 \\
\hline $\mathrm{Au} 4 \mathrm{f}(2+) 7 / 2$ & 89.19 & 2.576 & 776.509 \\
\hline $\mathrm{Au} 4 \mathrm{f}(2+) 5 / 2$ & 85.69 & 2.576 & 814.38 \\
\hline Unknown & 91.13 & 1.594 & \\
\hline
\end{tabular}

Notes: Peak positions, for GNP-L-aspartate and GNP-L-aspartate-TMZ, line-widths and quantified area are summarized.

\section{Publish your work in this journal}

The International Journal of Nanomedicine is an international, peerreviewed journal focusing on the application of nanotechnology in diagnostics, therapeutics, and drug delivery systems throughout the biomedical field. This journal is indexed on PubMed Central, MedLine, CAS, SciSearch $\AA$, Current Contents ${ }^{\circledR} /$ Clinical Medicine,

(1)

